\title{
Supplementary Information, S4.
}

Cyclic voltammograms of $\left(\mathrm{Bu}_{4} \mathrm{~N}\right)_{2}\left[\mathbf{1}^{2-}\right]$ and $\left(\mathrm{Bu}_{4} \mathrm{~N}\right)_{2}\left[2^{2-}\right] ; 0.05 \mathrm{M} \mathrm{Bu}_{4} \mathrm{NPF}_{6} / \mathrm{CH}_{2} \mathrm{Cl}_{2}, \mathrm{Pt}$ working electrode, versus ferrocene/ferricinium. Coulometric experiments were in sufficiently good agreement with the assignment of both processes as one-elctron processes.
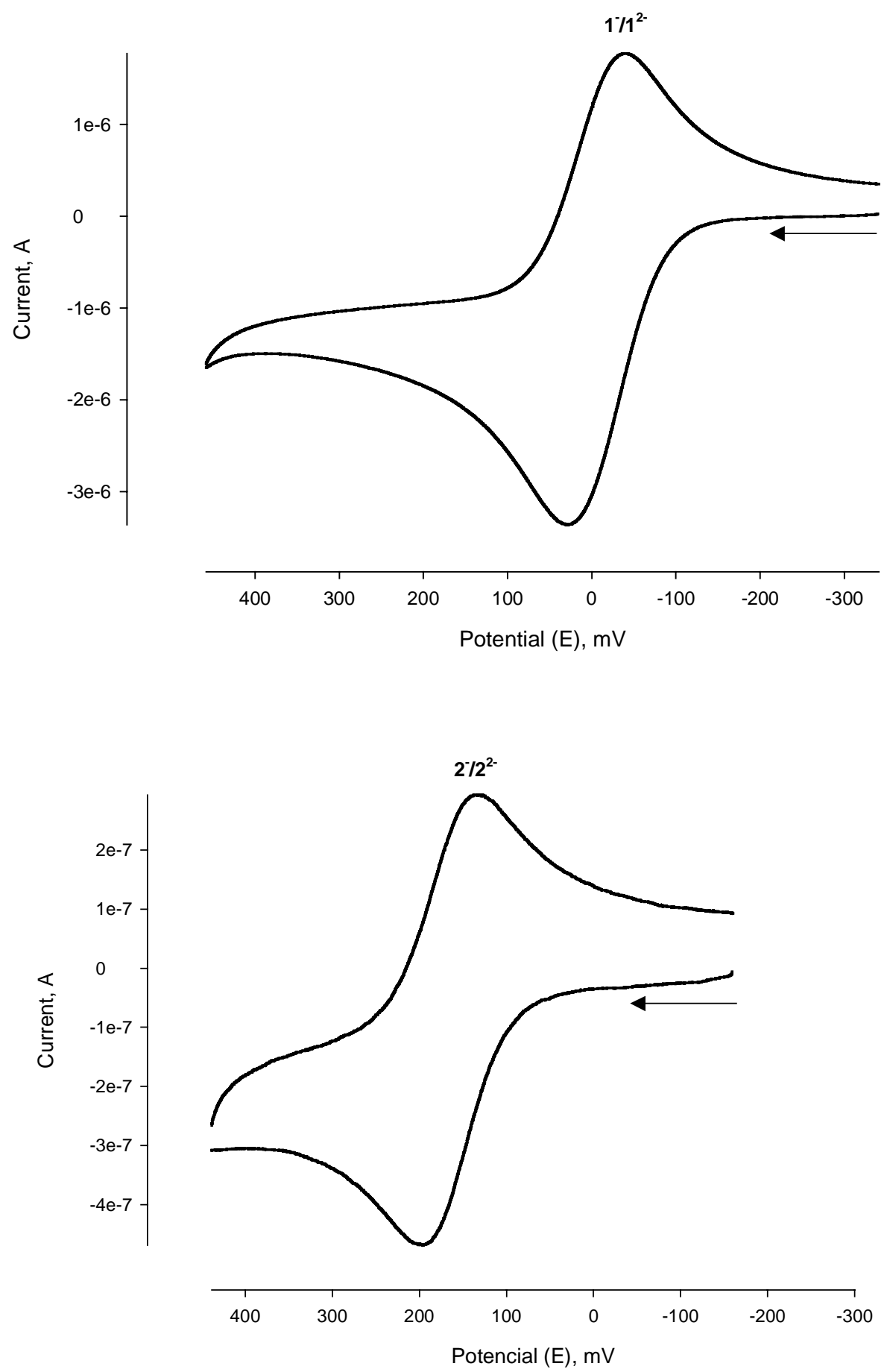